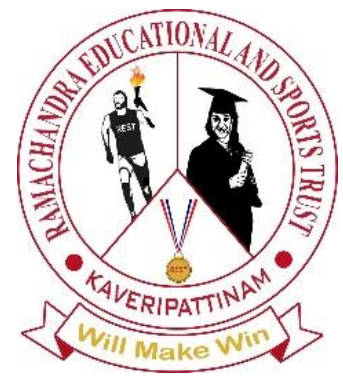

Recent trends in Management and Commerce

Vol: 2(1), 2021

REST Publisher

ISBN: 978-81-936097-6-7

Website: $\underline{\text { http://restpublisher.com/book-series/rmc/ }}$

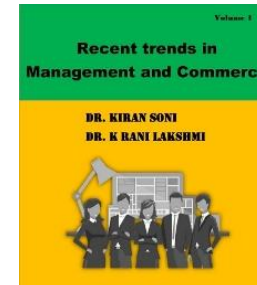

(4)

\title{
Perception of Food Labelling Among Supermarket Consumers of Thoothukudi
}

${ }^{1} X$. Sebastini Silva, ${ }^{2}$ Dr.T. Priyanka

1. PhD Research Scholars, St.Mary's College (Autonomous), Thoothukudi

2. Assistant Professor in Commerce, St.Mary’s College (Autonomous), Thoothukudi

Corresponding Author: sebastini@gmail.com

\begin{abstract}
Food Labelling is a printed, printed or graphic matter that is present on the label accompanying the food, or is displayed near the food, including that the purpose of promoting its safe or disposal. Food Labelling enables about the informed decision while purchasing and consuming the food products. Food label information assists consumers to better understand the nutritional value of food and enables them to compare the nutritional values of similar food products and to make healthy informed food choices. The objective of this paper is to determine level of awareness of the respondents of the information of food labels and also to explain the perception on usage of food labelling among the consumer of supermarkets in thoothukudi. Convenience sampling method is used in this research. For this purpose, the data was collected by the researchers personally based on the questionnaire conducted among 160 respondents. Food environment should be changed to control the rising health and economic burden from obesity and diabetics. Governments have to explore new formats and different types of information so that people can understand easily the content and to ensure that nutrition information is accessible
\end{abstract}

Keyword: food labelling, perception, supermarkets

\section{Introduction}

Consumers are increasingly concerned about their health and general well-being with the improvement of living standards . Labels on food packages provide important information such as date label, nutritional information, health warnings and net weight. A label serves the following three primary functions, namely, basic product information, health, safety, and nutrition information and it also acts as a vehicle for food marketing, promotion, and advertising (through label vignettes). In India, the food labelling act "Food Safety and Standards Regulations, 2011" gives guidelines for packaging and labelling of food items. Chemical substances are now being added to foods in order to make them into the vast array of processed foods available in the market.These help to make processed foods smaller in size and taste better, as well as improve their shelf life .It has been proved that these types of foods affect as physical, mental and social well-being of individuals . In today's situation consumers of supermarket are facing many difficulties before buying a food items such as product selection, availability choices and its use, as a result consumers find a wide range of food items in the market. Food label on prepackaged is the source of information and it guides the consumers in selection of food products. This study highlights about the consumer perception towards food labelling in supermarkets.Food label information assists consumers to better understand the nutritional value of food and enables them to compare the nutritional values of similar food products and to make healthy informed food choices based on the relevant nutrition information. According to Centre for Food Safety in Hong Kong, nutritional label is a systematic way of presenting nutrition information of food product. It is presented in a tabular format with headings such as "nutrition information", "nutrition fact', or "nutrition label". The food corporation of India has the authority to require nutritional labelling for most food products and to access nutritional information and to promote healthy food choices.

\section{Objectives}

To determine level of awareness of the respondents of the information of food labels and also to explain the perception on usage of food labelling among the consumer of supermarkets in thoothukudi.

Research methodology

Research design is the framework of research methods and techniques chosen by a researcher. An impactful research design usually creates a minimum bias in data and increases trust in the accuracy of collected data.

\section{Sampling Technique}

Convenience sampling is used in exploratory research where the researcher is interested in getting an inexpensive approximation of the truth.

\section{Sources of Data Collection}

Primary data:

Primary data was collected by preparing questionnaire.160 respondents are distributed but 145 questionnaire was filled correctly. 
Secondary data

Secondary data will consist of different literatures like books which are published, articles, internet and websites.

Study Area

Data has been collected from individuals at different super markets in different areas of Thoothukudi district during the period 02nd April to 30th March 2021.160 respondents were questioned at super markets in the following areas of Thoothukudi district headquarters.
a. Velavan Hyper Market
b. Vasantham Super Market
c. Rani Stores Super Market
d. Millers Super Market
e. Vanavil Super Market
f. Mangai Super Market
g. Sree Jayam Super Market
h. Barathi Super Market.

\section{Sample Size}

For the study, a sample size of 160 has been taken into reflection including both male, female, educated and uneducated and also with different levels of income.

\section{Statistical Tools Used}

The main statistical tools used are:

a. Pie Charts

b. Bar Diagrams

Analysis:

\section{Results Analysis and Interpretation Analysis}

Analysis is the process of breaking a complex topic or substance into smaller parts in order to gain a better understanding of it. Interpretation:

Interpretation is the act of explaining, reframing, or otherwise showing your own understanding of something.

\section{Gender of the respondents}

\begin{tabular}{|l|l|l|}
\hline Gender & Frequency & Percentage \\
\hline Male & 80 & 55.2 \\
\hline Female & 65 & 44.8 \\
\hline Total & 145 & 1000 \\
\hline
\end{tabular}

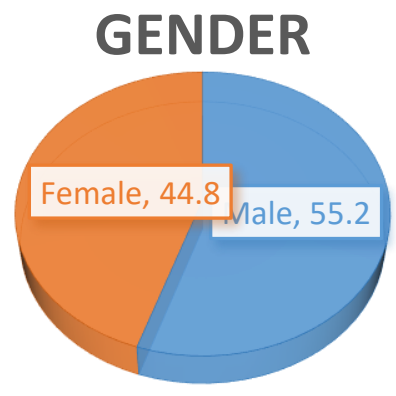

\section{Analysis:}

From the survey it was found that amongst 145 respondents $55 \%$ are male and $45 \%$ are female. Education of the respondents

\section{Educational}

54

$$
\begin{aligned}
& \text { No Formal Education } \\
& \text { Primary Education } \\
& \text { Secondary Education } \\
& \text { College/University }
\end{aligned}
$$




\begin{tabular}{|l|l|l|}
\hline Educational & Frequency & Percentage \\
\hline No Formal Education & 28 & 19.31 \\
\hline Primary Education & 23 & 15.86 \\
\hline Secondary Education & 40 & 27.59 \\
\hline College/University & 54 & 37.24 \\
\hline Total & 145 & 100 \\
\hline
\end{tabular}

\section{Analysis:}

From the survey it was found that amongst 145 respondents $19.31 \%$ of the people are not having any formal education, $15.86 \%$ are in primary completed stage, $27.59 \%$ have completed secondary education and $37.24 \%$ are with an education college/university.

\section{Occupation of the respondents}

\begin{tabular}{|l|l|l|}
\hline Occupation & Frequency & Percentage \\
\hline Employed & 58 & 40.00 \\
\hline Business & 13 & 8.97 \\
\hline House wife & 39 & 26.90 \\
\hline Peasants & 10 & 6.90 \\
\hline Others & 25 & 17.24 \\
\hline Total & 145 & 100 \\
\hline
\end{tabular}

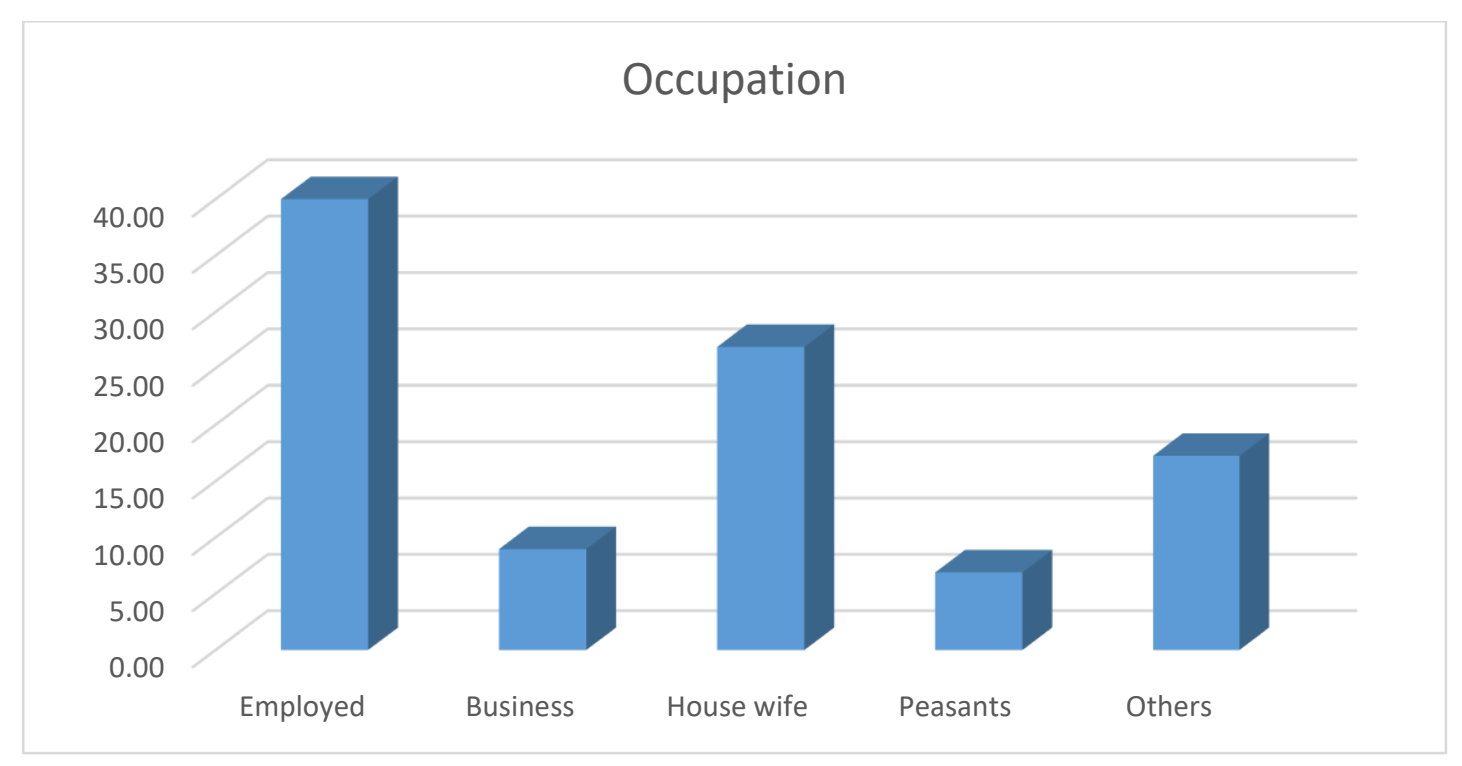

\section{Analysis:}

From the survey it was found that amongst 145 respondents $40 \%$ are employed, $8.97 \%$ are doing business, $26.90 \%$ are housewife, $6.90 \%$ are peasants and $17.24 \%$ are doing other works.

\section{Percentage of household food items of your family brought by you.}

\begin{tabular}{|l|l|l|}
\hline & & \\
\hline Food shopping for the Household & Frequency & Percentage \\
\hline Most & 33 & 22.76 \\
\hline Little & 81 & 55.86 \\
\hline None & 22 & 15.17 \\
\hline Total & 9 & 6.21 \\
\hline
\end{tabular}

\section{Analysis}

From the survey it was found that amongst 145 respondents $22.76 \%$ of the people do all their food shopping for their households, $55.86 \%$ are mostly do their shopping, $15.17 \%$ will do a little shopping and $6.21 \%$ are not doing any shopping. 


\section{Frequency of observing the food labels}

\begin{tabular}{|l|l|l|}
\hline Observation of Food labels & Frequency & Percentage \\
\hline Always & 41 & 28.28 \\
\hline Often & 46 & 31.72 \\
\hline Rarely & 31 & 21.38 \\
\hline Sometimes & 12 & 8.28 \\
\hline Never & 15 & 10.34 \\
\hline Total & 145 & 100 \\
\hline
\end{tabular}

Analysis:

\section{Observation of Food labels}

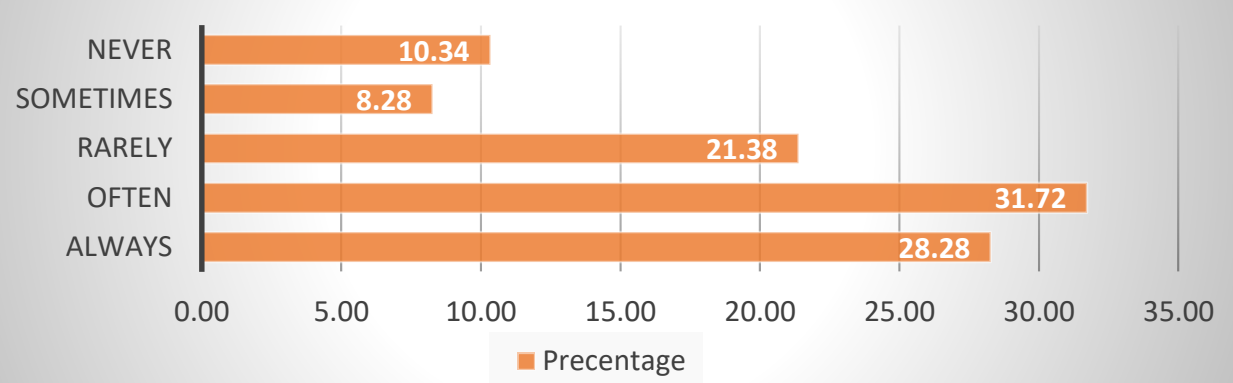

From the survey it was found that amongst 145 respondents $28.28 \%$ of the people always buy the food products after reading the labels on packages, $31.72 \%$ will read often, $21.38 \%$ will read rarely, $8.28 \%$ will read sometimes and $10.34 \%$ of the people don't read the labels on packages.

Understanding ability of the food label

\begin{tabular}{|l|l|l|}
\hline Understanding Ability & Frequency & Percentage \\
\hline Very Easy & 22 & 15.17 \\
\hline Somewhat Easy & 62 & 42.76 \\
\hline Very Hard & 24 & 16.55 \\
\hline Somewhat Hard & 37 & 25.52 \\
\hline Total & 145 & 100 \\
\hline
\end{tabular}

\section{Analysis:}

From the survey it was found that amongst 145 respondents $15.17 \%$ of the people think it is very easy to understand the labels on packages, $42.76 \%$ think somewhat easy, $16.55 \%$ think it is very hard, $25.22 \%$ think somewhat hard.

The amount of information on Food labels

\begin{tabular}{|l|l|l|}
\hline $\begin{array}{l}\text { The amount of information } \\
\text { on Food labels }\end{array}$ & Frequency & Percentage \\
\hline Too Much & 45 & 31.03 \\
\hline Right amount & 66 & 45.52 \\
\hline No Enough & 14 & 9.66 \\
\hline No Opinion & 20 & 13.79 \\
\hline Total & 145 & 100 \\
\hline
\end{tabular}

\section{Analysis:}

From the survey it was found that amongst 145 respondents $31.03 \%$ of the people feel amount of information on labels are too much, $45.52 \%$ feel that's the right amount, $9.66 \%$ think it is not enough and $13.79 \%$ people don't have any opinion.

\section{Influence of food label on your buying decision.}

\begin{tabular}{|l|l|l|}
\hline Influence of food label & Frequency & Percentage \\
\hline A great deal of influence & 38 & 26.21 \\
\hline A fair amount of influence & 44 & 30.34 \\
\hline Some influence & 9 & 6.21 \\
\hline Few influence & 21 & 14.48 \\
\hline No influence & 33 & 22.76 \\
\hline Total & 145 & 100 \\
\hline
\end{tabular}




\section{Analysis:}

From the survey it was found that amongst 145 respondents $26.21 \%$ people have a great deal of influence when buying, $30.34 \%$ are having a fair amount of influence, $6.21 \%$ have some influence, $14.48 \%$ have a little influence and $22.76 \%$ have no influence in it.

\section{Most familiar terms on pre-packaged food labels}

\begin{tabular}{|l|l|l|}
\hline Most familiar terms & Frequency & Percentage \\
\hline list of ingredients & 25 & 17.24 \\
\hline net content & 12 & 8.28 \\
\hline manufacture details & 3 & 2.07 \\
\hline country of Origin & 7 & 4.83 \\
\hline batch Identification & 3 & 2.07 \\
\hline manufacture date & 45 & 31.03 \\
\hline expiry date & 29 & 20.00 \\
\hline Storage Condition & 3 & 2.07 \\
\hline Nutrition Information & 18 & 12.41 \\
\hline Total & 145 & 100 \\
\hline
\end{tabular}

\section{MOST FAMILIAR TERMS}

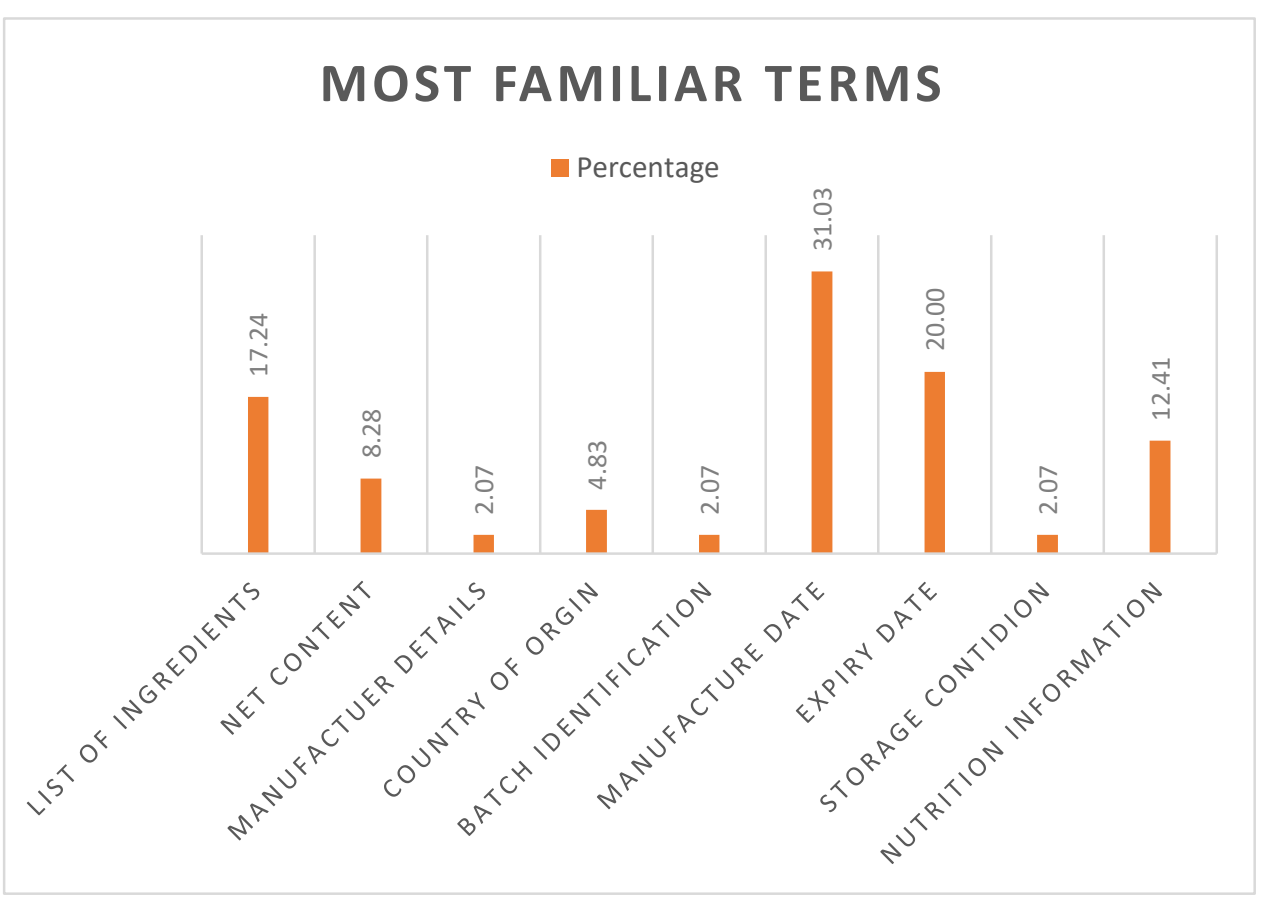

\section{Analysis:}

From the survey it was found that amongst 145 respondents' majority of the people look at the food label for knowing the manufacture date and expiry date followed by list of ingredients, nutrition, net content, country of origin, manufacture details, batch information and storage conditions.

\section{Importance of food labelling information.}

\begin{tabular}{|l|l|l|}
\hline Importance of food label & Frequency & Percentage \\
\hline yes & 97 & 66.90 \\
\hline no & 48 & 33.10 \\
\hline Total & 145 & 100 \\
\hline
\end{tabular}




\section{IMPORTANCE OF FOOD LABELING INFORMATION}

\section{Analysis:}

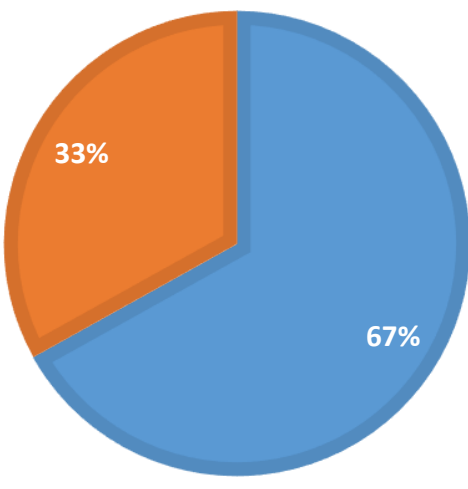

yes no

From the survey it was found that amongst 145 respondents $67 \%$ say yes to the importance of food labelling and $33 \%$ say no.

Reasons for reading nutrition information on food packages.

\begin{tabular}{|l|l|l|}
\hline Reason for Reading & Frequency & Percentage \\
\hline Product Comparison & 69 & 47.59 \\
\hline Curiosity & 6 & 4.14 \\
\hline Nutrition Advice & 28 & 19.31 \\
\hline Family members Habit & 13 & 8.97 \\
\hline Special Dietary needs & 29 & 20.00 \\
\hline total & 145 & 100 \\
\hline
\end{tabular}

\section{Analysis:}

From the survey it was found that amongst 145 respondents $47.59 \%$ read the nutrition information on packages for percent product comparisons, $4.14 \%$ due to curiosity, $19.31 \%$ for advice from nutrition counselling, $8.97 \%$ as a family member habits, $20 \%$ as special dietary needs.

\section{Discussion}

Overall, these studies reveal that use of food labels among the general public is generally high Male are using food labels significantly more often than women in the study. It also depicts that majority respondents are educated and among them most of them have completed college / university. It has been documented different levels of income and socio-economic status of the respondents. Most of them are employed and also states that they will read the details before buying food items for household purposes so that they can give the best product to their families. From the survey it was found that amongst 145 respondents $31.72 \%$ of the people will read the food labels often buy the food products after reading the labels on packages, $28.28 \%$ will read always, $21.38 \%$ will read rarely, $8.28 \%$ will read sometimes and $10.34 \%$ of the people don't read the labels on packages. It concludes that respondents are aware about food labels.From the survey it was found that $42.76 \%$ think somewhat easy to understand the labels on packages, $15.17 \%$ of the people think it is very easy to understand the labels on packages, $42.76 \%$ think somewhat easy, $16.55 \%$ think it is very hard, $25.22 \%$ think somewhat hard. $45.52 \%$ feel that the right amount of information is given and 31.03\% of the people feel amount of information on labels are too much, $9.66 \%$ think it is not enough and $13.79 \%$ people don't have any opinion. The results show more simple and precise food label will be easy for the buyer to read. It was found that $26.21 \%$ people have a great deal of influence when buying, $30.34 \%$ are having a fair amount of influence, $6.21 \%$ have some influence, $14.48 \%$ have a little influence and $22.76 \%$ have no influence in it. Thus, we can conclude that food label plays a few roles in buying and it has to be increased. Majority of the people look at the food label for knowing the manufacture date and expiry date followed by list of ingredients, nutrition, net content, country of origin, manufacture details, batch information and storage conditions. From the survey it was found that majority of people say food label is important. From the survey it was depicts $47.59 \%$ read the nutrition information on packages for percent product comparisons, $4.14 \%$ due to curiosity, $19.31 \%$ for advice from nutrition counselling, $8.97 \%$ as a family member habits, $20 \%$ as special dietary needs.

\section{Conclusion}

Food labels on pre-packaged foods are a cost-effective population level intervention with unparalleled reach. However, governments have to explore new formats and different types of information so that people can understand easily the content and to ensure that nutrition information is accessible. Food environment should be changed to control the rising health and economic burden from obesity and diabetics. There is an immediate action should be done for displaying nutrition information on all food items specially on pre-packed food items and food outlets so that it would lead to increase the impact of food labelling regulations and harmonizing nutrient information across information channels. 


\section{Bibliography}

1. S Simmaky," Assessment of Consumer Awareness on Food Labels and the Effect of the Level of Awareness on Buying Behaviour of Consumers in Jaffna District", Proceedings of 8th International Research Conference, KDU, Published November 2015

2. Heroux, L., Laroche, M. and McGown, K. L. (1988) Consumer Product Label Information Processing: An Experiment Involving Time Pressure and Distraction, Journal of Economic Psychology, 4: 263-272.

3. Food Safety and Standards Authority of India. Food Safety and Standards (Packaging and Labelling) Regulations. New Delhi: Government of India; 2011. Available from: http://www.fssai.gov.in/Portals/0/Pdf/ Food\%20Safety\%20and\%20standards\%20(Packaging\%20and\%20～Labelling)\%20regulation,\%202011.pdf. [Last accessed on 2016 Jan 20].

4. Millstone, E. Lang. T (2003). The Atlas of Food. Who Eats What, Where and Why, London; Earthscan Publications.

5. Uusitalo, U. Pietinen, P. and Puska, P. (2003). Dietary Transition in Developing Countries: Challenges for the Chronic Diseases Prevention in Globalization, Diets and Non-communicable Diseases WHO Geneva

6. Ajala, J. A. (2006). Understanding Food and Nutrition. Ibadan: May Best Publications p.xiv.

7. Al - Tamimi and Company (2004) Standardization and classification in the UAE: Retrieved from Centre for Food Safety (2006) Benefit of Nutrition information on Food Labels. Available at http:ww.cfs.gov.hk/ English/ program_nifl/ programme_nifl_02.html.

8. (Source: www.cfs.gov.hk)

9. Vemula SR, Gavaravarapu SM, Mendu VV, Mathur P, Avula L. Use of food label information by urban consumers in India - A study among supermarket shoppers. Public Health Nutrition 2014; 17:2104 14.

10. Nayga RM., Jr. Nutrition knowledge, gender and food label use. J Consumer Affair 2000; 34:97-112. [Google Scholar]

11. https://www.highspeedtraining.co.uk/hub/importance-of-food-labels/

12. Kreuter MW, Brennan LK, Scharff DP, Lukwago SN. Do nutrition label readers eat healthier diets? Behavioural correlates of adults' use of food labels. Am J Prev Med 1997; 13:277-83. [PubMed] [Google Scholar] 